\title{
EcoAction Mobile App: A Game Practice for Eco-activist
}

\author{
Herbert V. Rosal, Joshua Ry F. Borilla, Roland Jay D. De Guzman, Jan Alfred P. Macalintal, Ian \\ Vince N. Obille, Ma. Corazon Fernando Raguro ${ }^{+}$, and Dr. Ace C. Lagman \\ FEU Institute of Technology, Philippines
}

\begin{abstract}
Environmental awareness enables us to take measures in protecting and maintaining the environment. Moreover, video games are available everywhere as a means to not only entertain, but also to develop one's skills. They may be used as a teaching tool while still being fun to play to instill healthy habits, especially when it comes to the environment. This paper presents the development of EcoAction - a tap and drag 2D Android game that promotes environmentalism. We describe the game design of EcoAction and provide a validated questionnaire for assessing the aesthetics and gameplay. Results demonstrate that the received positive responses for its well-designed gameplay and appealing visuals. Therefore, videogames like EcoAction can be used as an awareness platform to encourage players to adopt environmental practices.
\end{abstract}

Keywords: Environmental Awareness, Video Games, Tap and Drag, Android Game, Environmental Practice

\section{Introduction}

Environmental issues are limitless, as they continue to arise regularly, and they have the potential to have terrible effects not only on our planet but also on all living beings. To address these concerns, we must encourage individuals to be environmentally conscious. It helps individuals understand the desperate need to take drastic steps to avoid damaging the environment [1,2] and repair the damage done by human beings. Knowledge encourages environmental improvement and promotes irreplaceable resource management [3]. Today, video games are getting increasingly popular, and they are providing players with a clear interpretation of the game's storyline [4]. It provides players with the implications of their behavior through gameplay that might tie to our culture and environment, based on the path the player has selected [5]. We will alter our planet little by using smartphones to become an asset to promote environmental awareness [6]. Thus, the project we aim to create is a 2D mobile casual game that encourages environmental stewardship, depicted in the five minigames that the player must complete getting points.

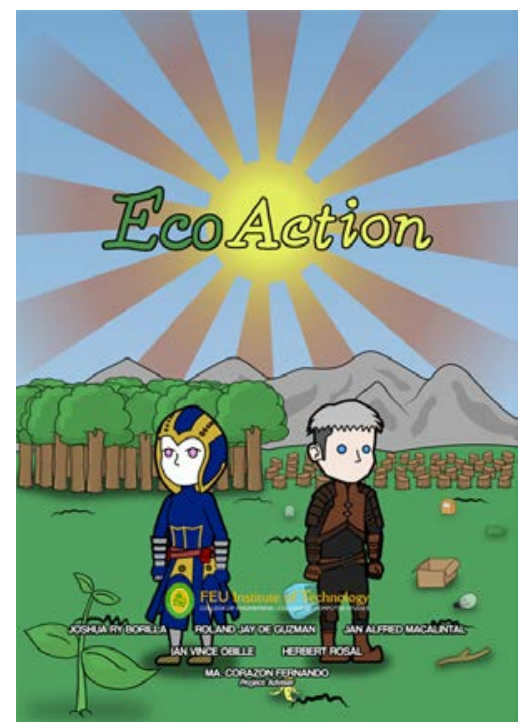

Fig. 1: Official Game Poster of EcoAction

\footnotetext{
+ Corresponding author. Tel.: +639154150445

E-mail address: mgfernando@feutech.edu.ph
} 
The figure above shown is the official game poster of EcoAction which would help to promote the game. General Objective:

To create a two and a half dimensional mobile game for android that encourages good practice on taking care of the environment.

Specific Objectives:

1) To create five (5) mini games about environmental practices.

2) To develop 2D models for all objects.

3) To implement music and sound effects in the game.

4) To create a game that gives motivation about environmental practices.

\section{Related Literature and Games}

Based on a study, we now live in a world where each generation will be a generation of gamers, with 174 million gamers in the United States alone [7]. Creating games that help us appreciate our surroundings will benefit not just the environment [8] but also ourselves. According to ERA Climate [9], if each of us can be more conscious of environmental issues, we can have a significant effect. Games with clever architecture will take players to the far past and educate them about the history of life. Predicting games, on the other hand, would enable us to see the consequences of our future acts or inaction [10]. According to Saikat (2017), it is possible to turn environmental education from drab textbooks into fun games. This style of game promotes environmental awareness while both being entertaining and encouraging. Choosing appropriate methods and paradigms for designing and testing such programs, as well as effectively blending the "fun" [11] element with messages, is still an active research challenge. The game could be able to assist society in reducing the negative effects and increasing knowledge of their environment. And if it is the government's responsibility [12] to protect the environment, every resident has a responsibility to properly conserve and preserve the environment's resources. Awareness of environmental problems will benefit both the environment and humans, as both are dependent on the sustainability of the other. The maintenance of ecological stability and a stable ecosystem has thus become important.

In a study, there are several advantages of playing video games, including improved basic visual functions, improved concentration and diligence, improved executive performance, and improved job-related abilities[13]. Aside from their amusement appeal, games have a lot of good potential [14], and they've had a lot of popularity when they're built to solve a problem or teach a skill. According to recent studies, playing video games repeatedly will affect player behavior and increase awareness of environmental issues. The study "The Educational Benefits of Computer Games" [15, 16] looked at persuasion games to encourage environmental education by raising environmental awareness. Given the global environmental challenges[17], it was seen as a vital key to dealing with the issues. The majority of participants thought the game was a useful and enjoyable teaching method. Despite the restrictions imposed by the game's time limits, the majority of participants found it to be an important teaching method [18]. Souza et al. (2019) created Save The Ocean, a two-player 2D game for the PC platform in which the two players take on the roles of sharks fighting to collect ocean waste. The game was good in interacting with the colors used in the recycling bins, but it failed to teach how different forms of waste had different impacts on the oceans. People would be more inspired and amused when learning about environmental concerns if they were taught by a video game.

\section{Materials and Method}

The game is entitled "EcoAction" - a tap and drag 2D game in which players are brought into the scene help the main characters: Chiroo and Emiroo, and finish the objective of the said scene. The game is designed for Android mobile platform. The game is set in a place called Viridion, a town in planet Terrakion which was once a and prosperous place, now tainted by the waste and misdeed of the inhabitants of the villages. After the Vandalians defeated, Viridion become more polluted because of the after the battle of the Ecoforce to the Vandalians. Econians need help of the player to clean up the mess and restore the beautiful scenery of Viridion once again. 
Table 1: Game Scenes of EcoAction

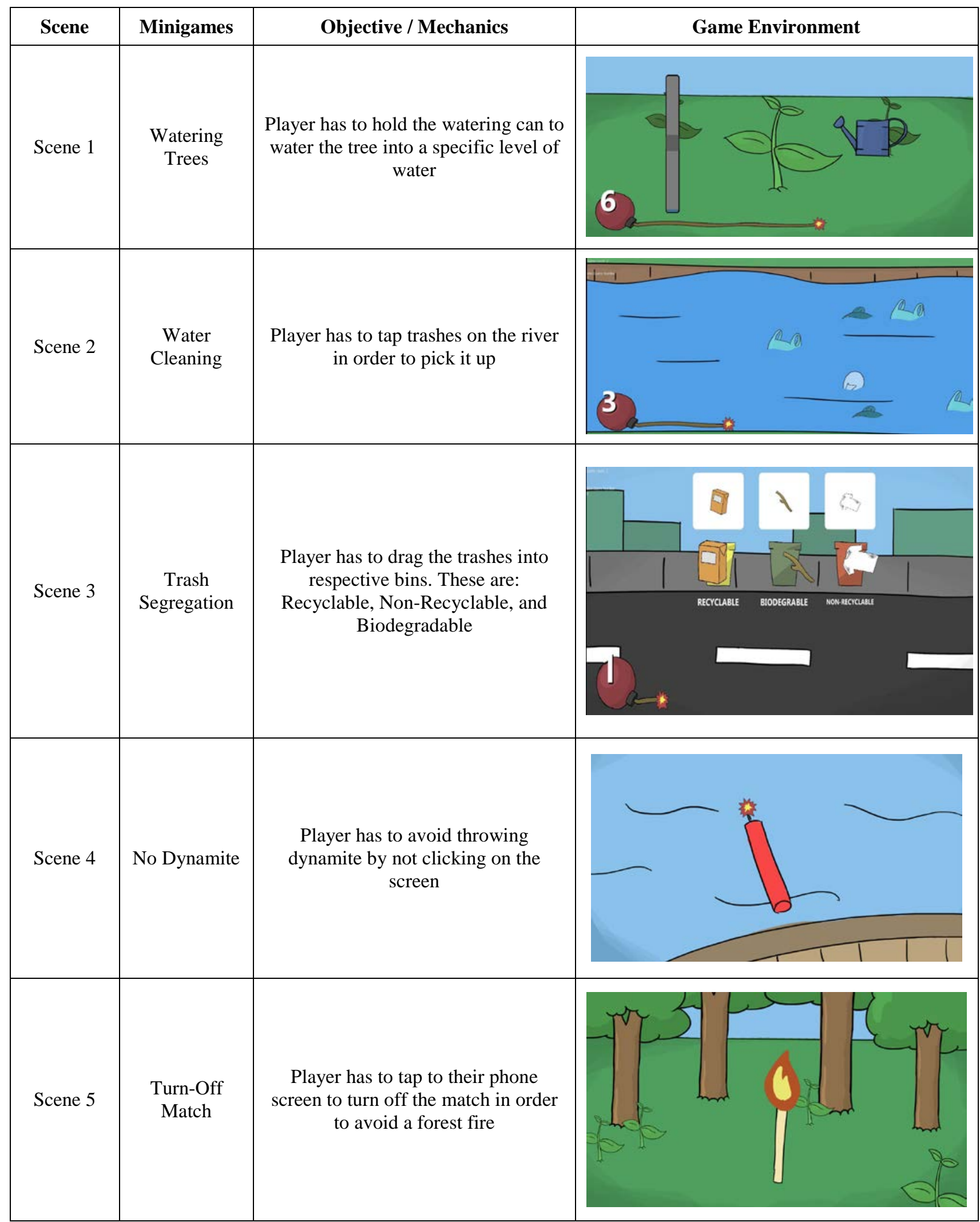

A. Game Mechanics

EcoAction is composed of five scenes which are random (See Table 1). As the player progresses throughout the game, there is a time limit per round so that the player can feel the fast pacing of the game. The player must complete the minigames (See Table 1), earn points and get a high score. If the player spent all of the three tries, the game will be over and it will show what the score player the gets. The camera angle 
of the game is set to orthographic view so that the player can navigate well into the entire scene and objectives of the game. The player has a wide range of tapping and dragging, making it easier to the player to complete the objectives into the game.

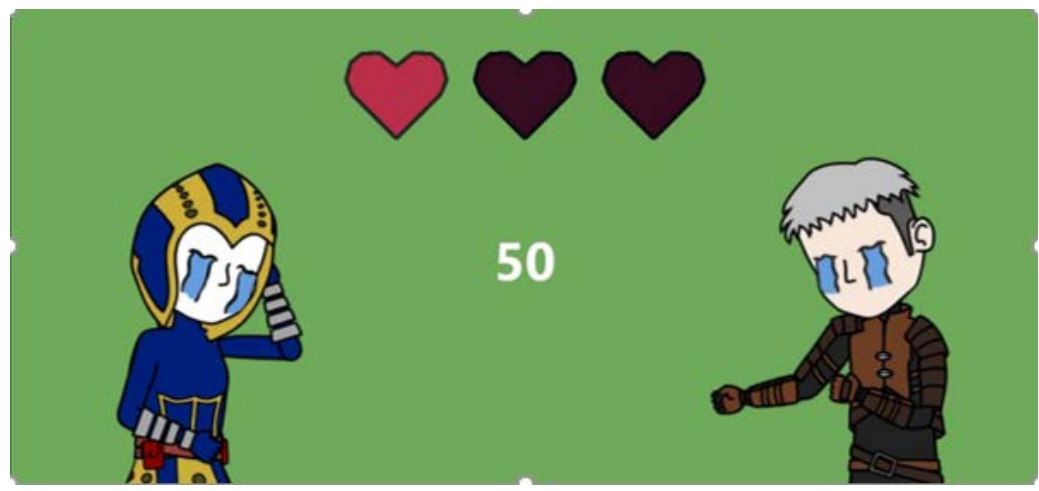

Fig. 2: Game Protagonists Emiroo and Chiroo (left to right)

Figure shown above the scene when the play did not complete the objective of the minigame. The player has only three lives into the game. If the player loses a life, the player will get a deduction from the current score that the player has.

\section{B. Game Evaluation and Statistical Treatment}

A total of ten (10) faculty members of the FEU Institute of Technology specifically IT department helps the team in discussing, answering the provided questionnaire and providing insights to the game while watching the gameplay presentation via Google Meet. The proponents used the technique of Convenience Sampling because findings are much simpler and easy to get. This project's statistical treatment will use Analysis of Variance (ANOVA). This is to decide which age level, ethnicity, or their income would be of great importance to the game as the project is the target audience to reach. The evaluation used a questionnaire, a validated instrument for the game experience with constructs such as gameplay and aesthetics. Respondents were invited to attend the virtual meeting for the showcase of the game.

Scrum Methodology which will be used by the proponents as a development model. Using the Scrum, the proponents will have a faster development time and its power to adapt in the face of changing circumstances and demands.

\section{Results and Discussion}

In the following results, the findings obtained from the game evaluation during an online virtual meeting composed of ten respondents who are faculty members of FEU Institute of Technology by watching the gameplay of the project. As a reference, the Likert scale for the evaluation questionnaire. The highest point out of all ratings is 4.51 to 5.00 with a verbal interpretation of "Strongly Agree" while the lowest point is 1.00 to 1.50 with a verbal interpretation of "Strongly Disagree".

Table 2: Gameplay According to Respondents

\begin{tabular}{|c|c|c|}
\hline Description & Mean & Verbal Interpretation \\
\hline The Mechanics of the Game is Easy to Understand & 4.4 & Agree \\
\hline $\begin{array}{c}\text { The Game Encourages Good Practice on Taking Care of the } \\
\text { Environment }\end{array}$ & 3.8 & Agree \\
\hline The Game Implements Fun and Interactive Between the User and Game & 4.8 & Agree \\
\hline The Game Controls are Well Implemented & 4.2 & Agree \\
\hline The Stages of the Game are Well Balance to Each Other & 3.8 & Agree \\
\hline TOTAL & $\mathbf{4}$ & Agree \\
\hline
\end{tabular}

Table shown above is the summary of the Gameplay evaluation. The mechanics of the game is easy to understand got a mean score of 4.4 which means the respondents are agree that the game is easily understood. Next is the game encourages good practice on taking care of the environment which got a 3.8 meaning that 
the respondents also agrees that the game shows environmental practices. Next is the game implements fun and interactive between the user and game got a mean score of 4.8 meaning that the respondents agreed that the game implements a fun and challenging way to play the game as it shows that the game has time limit. Next is the game controls are well implemented got a mean score of 4.2 which means the respondents agreed that the game is a trap and drag fast paced. And lastly, the stages of the games are well balance to each other got a mean score of 3.8 which means that the respondents also agrees that the game is balanced due to its time limit and being fast paced as the player progress throughout the game.

Table 3: Aesthetics According to the Respondents

\begin{tabular}{|c|c|c|}
\hline Description & Mean & Verbal \\
\hline The Game Shows How to Take Care of the Environment & 3.8 & Agree \\
\hline $\begin{array}{c}\text { The Game Establishes a Connection Between the User and } \\
\text { Environment }\end{array}$ & 4.4 & Agree \\
\hline The Minigames are Able to Portray Real-Life Scenario & 4.4 & Agree \\
\hline The Characters and the Environment Complement Each Other & 4.2 & Agree \\
\hline The Stylized Art Style of the Game is Appealing & 3.8 & Agree \\
\hline TOTAL & $\mathbf{4 . 1 2}$ & Agree \\
\hline
\end{tabular}

Table shown above is the summary of the Aesthetics evaluation. The game shows how to take care of the environment got a mean of 3.8 with agree which means the game shows its effectiveness to affect the player to take care of the environment. Next is the game establishes a connection between the user and environment got a mean of 4.4 which means the respondents agreed that the game has impact on the player. Next is the minigames are able to portray real-life scenario got a mean score of 4.4 which means the game applied real life. Next is the characters and the environment complement each other meaning that the visuals, UI and characters in the game are related and the styles are the same. And lastly the stylized art style of the game is appealing got a mean score of 3.8 which means that the game is appealing to the respondents.

\section{Conclusion}

The game "EcoAction!" showed the good practices in taking care of the environment. It presented possible effects of doing the right thing and doing the wrong thing. Doing good practices for the environment can help even the simplest thing. The project was able to do this by creating a 2D tap and drag action game with five (5) mini games that task the player to help protect the environment. The Objectives of the game were answered through a survey, which composed of (3) criteria of the game. The respondents for the technical questionnaire were professors from the FEU Institute of Technology. The proponents successfully met the objective by which reflected by the survey results and feedbacks for the adjustment and completion of the game.

\section{Recommendations}

Based on the information we gathered, the respondents believe that the game should include more mini games in the future that focus on present and future climate change challenges. Respondents suggested adding "achievements" and a "leader board" that includes all online players' high scores to make the game more competitive and enjoyable for the users.

\section{References}

[1] Branco, MAA, Weyermüller, AR, Müller, EF, Schneider, GT, Hupffer, HM, Delgado, J, Mossman, JB, Bez, MR, \& Mendes, TG. (2015). Games in the environmental context and their strategic use for environmental education. Brazilian Journal of Biology, 75(2, Suppl. ), 114-121. Epub May 00, 2015.https://doi.org/10.1590/1519-6984.0413

[2] G, ANBALAGAN \& Viswanathan, Shanthi. (2015). A STUDY ON ENVIRONMENTAL AWARENESS AND RELATED PRACTICES AMONG THE HIGH SCHOOL STUDENTS AT MADURAI DISTRICT, TAMIL NADU. Indian Streams Research Journal. 5. 1-9.

[3] Goncharova, M. (2012). Planet Play: Designing a Game for Children to Promote Environmental Awareness. 
Retrieved January 27, 2021, from https://www.ojcmt.net/download/planet-play-designing-a-game-for-children-topromote-environmental-awareness.pdf

[4] Hartami, A. (n.d.). Designing a Persuasive Game to Raise Environmental Awareness Among Children: A Design Science Research. Retrieved May 15, 2018, from http://jultika.oulu.fi/files/nbnfioulu-201805312053.pdf

[5] Gaver. (2012, October 4). Play is not just mindless entertainment, but an essential way of engaging with and learning about our world and ourselves. Retrieved from https://www.ojcmt.net/download/planet-play-designing-agame-for-children-to-promote-environmental-awareness.pdf

[6] Souza, Gabriel \& Mesquita, Renzo \& Lima, Phyllipe \& Guerra, Eduardo \& Capistrano, Isabella. (2019). Save the Ocean: A Game for Environmental Awareness. Retrieved from https://www.researchgate.net/publication/336563525_Save_the_Ocean_A_Game_for_Environmental_Awareness

[7] Lukosch, H., Kurapati, S., Groen, D., \& Verbraeck, A. (2016). Microgames for Situated Learning. Simulation \& Gaming, 47(3), 346-367. doi:10.1177/1046878116635468

[8] Gardeli, A., Vosinakis, S., Englezos, K., Mavroudi, D., Stratis, M., \& Stavrakis, M. (n.d.). Design and Development of Games and Interactive Installations for Environmental Awareness. Retrieved December 8 https://www.researchgate.net/profile/Spyros_Vosinakis/publication/321726285_Design_and_Developmentof_Ga mes_and_Interactive_Installations_for_Environmental_Awareness/links/5a2fbef5a6fdccbf7eeefb8f/Design-andDevelopment-of-Games-and-Interactive-Installations-for-Environmental-Awareness.pdf

[9] Era Environment. (2018, May 17). Reasons Why We Should Care About the Environment. Retrieved January, 2021, from https://www.eraenvironnement.com/reasons-why-we-should-care-about-the-8927environment/\#sthash.eV26UatB.dpbs

[10] Hanno, \& Hirsch, B. (n.d.). Recent studies claim that the repeated playing of (computer) games can influence the player's behavior. Retrieved from https://www.researchgate.net/publication/228952909_Raising_Awareness_for_Environmental_Issues_through_M obile_Device_Based_Serious_Games

[11] Gray. (2015, February 20). Cognitive Benefits of Playing Video Games. Retrieved from https://www.psychologytoday.com/us/blog/freedom-learn/201502/cognitive-benefits-playing-video-games

[12] Mcgonial, J. (2011, February 1). Reality is Broken: Why Games Make Us Better and How They Can Change the World by Jane McGonigal. Retrieved from https://www.goodreads.com/book/show/7821348-reality-is-broken Bucer, J. (n.d.).

[13] Griffiths, M. (2002). Research going back to the early 1980s has consistently shown that playing computer games leads to reduced reaction times. Retrieved from https://www.researchgate.net/publication/284491180_The_educational_benefits_of_videogames

[14] Eugenio, S. (2020, February 20). 8 Cognitive Benefits of Playing Video Games for Kids. Retrieved from https://www.engadget.com/2017/02/09/8-cognitive-benefits-of-playing-video-games-for-kids/

[15] Turner, A. P., \& Martinek, T. J. (2013, February 22). An Investigation into Teaching Games for Understanding: Effects on Skill, Knowledge, and Game Play. Retrieved February, from https://www.tandfonline.com/doi/abs/10.1080/02701367.1999.10608047

[16] Basu, S. (2017, December 14). 10 Environmental Games That Teach Kids About Earth, Ecology, and Conservation. Retrieved January, 2021, from https://www.makeuseof.com/tag/10-environmental-games-teachkids-earth-ecology-conservation/

[17] Morganti, L., Pallavicini, F., Cadel, E., Candelieri, A., Archetti, F., \& Mantovani, F. (2017). Gaming for Earth: Serious games and gamification to engage consumers in pro-environmental behaviours for energy efficiency. Energy Research \& Social Science, 29, 95-102. doi:10.1016/j.erss.2017.05.001

[18] Dahiya, N., \& Ritu. (2013). A Study of Environmental Awareness and Attitude Towards Environmental Degradation of Senior Secondary School Students. Retrieved January 27, 2021, from http://www.ijemhs.com/Published\%20Paper/Volume\%2002/Issue\%2001/IJES\%2004/IJEMHSDec13_15_26_Neel am_Ritu.pdf 